\title{
BREAST CANCER AND SOME EPIDEMIOLOGICAL FACTORS: A HOSPITAL BASED STUDY
}

\author{
JABEEN $\mathrm{S}^{1}$, HAQUE $\mathrm{M}^{2}$, ISLAM J ${ }^{3}$, HOSSAIN MZ ${ }^{4}$, BEGUM A ${ }^{5}$, KASHEM MA ${ }^{6}$
}

\begin{abstract}
:
Objective: The aim of this study was to determine risk factors associated with breast cancer in the National Institute of Cancer Research and Hospital, Dhaka, Bangladesh.

Methodology: A case control study was conducted from July 2009 to June 2010, on 262 biopsy proven cases of breast cancer from National Institute of Cancer Research and Hospital and 262 matched controls of acute diseases from Dhaka Medical College Hospital. Religion, residential status and age ( \pm 2 years) were matched. Statistical analysis was carried out using conditional logistic regression, odds ratios, chi-square and t- test with SPSS software (V-17).

Results: Multivariate analysis showed that higher education (OR=1.72), personal income $(O R=5.71)$, history of induced abortion $(O R=20.62)$, history of breast feeding $(O R=7.91)$, OCP users $(O R=1.47)$, current smokers $(O R=6.78)$, personal history of breast disease $(O R=10.99)$, family history of breast cancer $(O R=3.85)$ and family history of other cancer $(O R=2.21)$ were risk factors for breast cancer. Furthermore, having menarche at an early age $(O R=0.35)$, giving birth to an early age $(O R=0.35)$, early menopause $(O R=0.22)$, longer duration of breast feeding $(O R=0.30)$, parity of 2 and more $(O R=0.29)$ and regular physical activity $(O R=0.58)$ were shown to be protective factors.

Conclusion: Physical inactivity, being menopause, positive family history of breast cancer and history of induced abortion were found important risk factors. Longer duration of breast feeding should be encouraged for its protective effect. Study revealed that the women who have one or more of the above risk factors should be given special attention for breast cancer prevention.
\end{abstract}

Key Words: Breast cancer, induced abortion, breast feeding, physical activity

J Dhaka Med Coll. 2013; 22(1) : 61-66.

\section{Introduction:}

Breast cancer is the most common type of cancer in women and considered as a major public health problem. It is a leading cause of cancer death, second only to lung cancer. Owing to its huge prevalence through out the world breast cancer prevention is one of the major concerns for every woman ${ }^{1}$.

About 200,000 women in the United States are diagnosed with breast cancer each year. However, not all women have the same risk of developing breast cancer during their lifetime. Studies have shown that certain factors, called risk factors, increase the likelihood that a woman will develop breast cancer. Many of these risk factors are not reversible, but some can be modified. Not all factors increase a woman's chance of developing breast cancer equally. Some factors (such as inheriting a breast cancer-related gene) increase a woman's risk of breast cancer more than others ${ }^{2}$.

The presence of breast cancer risk factors does not mean that cancer is inevitable: many women with risk factors never develop breast cancer. Instead, risk factors help to identify women who may benefit most from screening

1. Dr. Suraiya Jabeen, Assistant Professor, Community Medicine Department, Dhaka Medical College, Dhaka

2. Prof. Musarrat Haque, Head, Department of Community Medicine, Shaheed Suhrawardy Medical College, Dhaka

3. Dr. Md. Johirul Islam, Assistant Professor, Cancer Epidemiology, National Institute of Cancer Research \& Hospital, Mohakhali, Dhaka.

4. Dr. Mohammad Zaid Hossain, Assistant Professor, Department of Medicine, Dhaka Medial College, Dhaka

5. Dr. Atiya Begum, MPH Student, National Institute of preventive \& Social Medicine, Mohakhali, Dhaka

6. Dr. Md. Abul Kashem, Registrar, Department of Medicine, Sir Salimullah Medical College, Dhaka

Correspondence : Dr. Suraiya Jabeen, Assistant Professor, Community Medicine Department, Dhaka Medical College, Dhaka, E-mail:jabeens2009@gmail.com 
or other preventive measures. Individual women should work with their clinicians to determine their own personal risk of breast cancer, based upon their own circumstances. The average woman has about a 10 to 15 percent chance of developing breast cancer if she lives into her 90s. On the other hand, the risk of developing breast cancer in a woman with a strong family history of the disease who has inherited one of the genes that predispose her to breast cancer is over 50 percent ${ }^{3}$.

In 1980 , breast cancer represented $18 \%$ of all cancers in women throughout the world. The worldwide incidence of breast cancer is increasing by $1.5 \%$ per annum and is influenced by geographical factors and by age. In France, this disease represents 19\% of cancer deaths in women and is the commonest cause of cancer death in women. Several risk factors have been suspected, but many points remain obscure. The age of the menarche, the age of menopause, parity, age of the first pregnancy, family history of breast cancer influence the incidence of breast cancer. The use of oral contraceptives and hormone replacement therapy for menopause do not appear to affect the development of malignant breast disease, except, perhaps, in certain subgroups of patients, but this remains to be confirmed. The risk is increased by a fatty diet and by excessive alcohol consumption ${ }^{1}$.

\section{Materials and Methods:}

This case- control study was conducted on females, aged 20 years and above. Data was collected from incident (with in 6 months of diagnosis) breast cancer cases, confirmed histopathologically, cytopathologically, radiologically or by the oncologists, from National Institute of Cancer Research and Hospital (NICRH). Matched controls were collected from Dhaka Medical College (DMCH), after fulfilling inclusion and exclusion criteria and giving informed consent during the study period.

The required sample size of this case-control study was calculated by estimating an odds ratio with specified relative precision, from WHO's sample size determination in health studies manual ${ }^{4}$. Calculated sample size was
434 in each group. For convenience, we recalculated the sample size and limited it to 262 respondents in each group. Here, purposive sampling technique was followed.

An interview schedule with semi-structured questionnaire was used for data collection. No sensitive or privacy invasive questions were asked. Statistical analysis was carried out using conditional logistic regression, odds ratios, chi-square and t- test with SPSS software (V-17).

\section{Results:}

This case-control study was conducted among 524 respondents, with equal number of cases and controls, majorities (71\%) were from Dhaka division. About $66 \%$ of the respondents were from rural and $34 \%$ from urban areas. Among them $71 \%$ breast cancer cases were from urban and $58 \%$ from rural population. The mean age of the cases was $43.55(\mathrm{SD} \pm 9.63)$ years. Majorities (28\%) of the respondents were in 4145 years age group (Fig: 1 ).

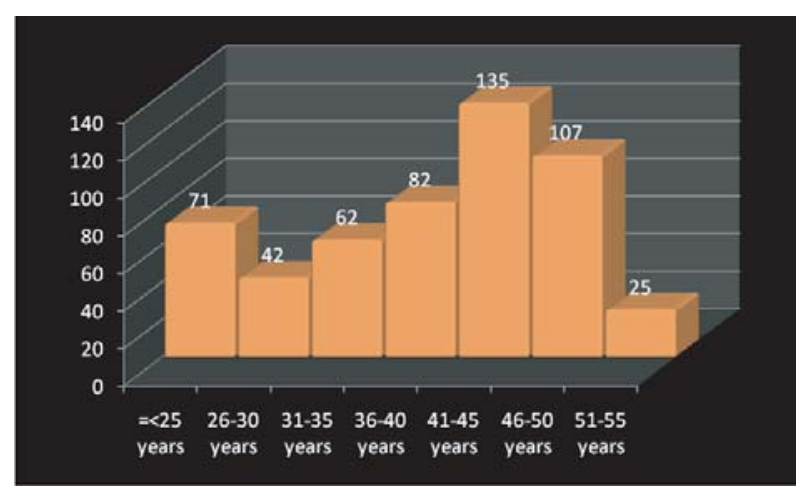

Fig.-1: Histogram showing age group distribution of the respondents

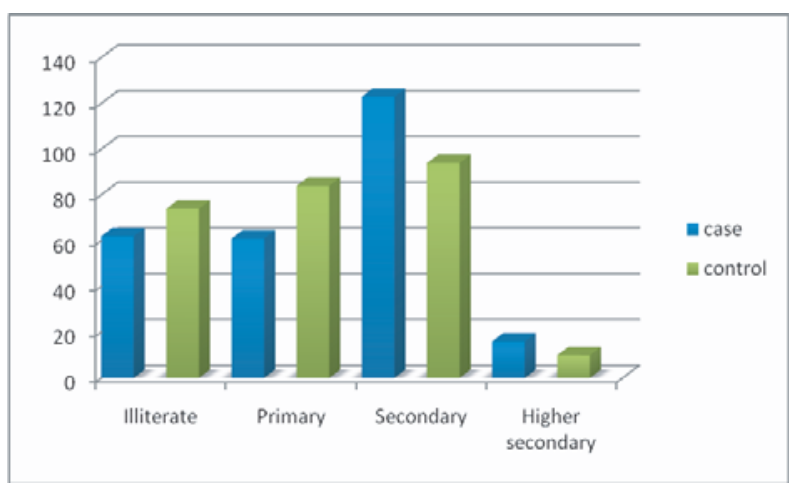

Fig.-2: Multiple bar diagram showing respondents' educational level 
Fifty four percent of the respondents were educated from primary and below level and rest 46\% were from secondary and above level (Fig: 2). Among the primary and below level, majority belonged to control group and from secondary and above level majority were from breast cancer cases.

About $97 \%$ respondents were currently married and rests were widow. The entire widow's were from breast cancer group. Respondents' occupational status showed that, $79 \%$ were housewife among them majority was from control group, $11 \%$ were service holder, $8 \%$ garments worker and rest $2 \%$ had different types of businesses.

Seventy nine percent had no personal income, among them most were from control group. About 21\% respondents had income, among them majority were from breast cancer group.

Respondents mean age at menarche was 11.73 (SD \pm 1.33$)$ years for breast cancer cases and $11.47(\mathrm{SD} \pm .71)$ years for controls, majority (54\%) had menarche at eleven or below age. A highly significant $(\mathrm{p}<0.001)$ association was seen between breast cancer and their age at menarche. Odds ratio $(\mathrm{OR}=0.35)$ showed that those who had history of menarche at $\leq 11$ years were 0.35 times less at risk of developing breast cancer than those who had menarche after $>11$ years.

Respondents mean age of giving first birth was 19.41 ( $\mathrm{SD} \pm 2.40$ ) years for breast cancer cases and $16.37(\mathrm{SD} \pm 1.16)$ years for controls. About $90 \%$ had their first child at or below 21 years, among them majority were from control group and rest $10 \%$ had their first baby above 21 years were all most all were from breast cancer group. A highly significant $\left(\chi^{2}=65.44 ; \mathrm{df}=8 ; \mathrm{p}<0.001\right)$ association was seen. Odds ratio $(\mathrm{OR}=0.35)$ showed that those who gave birth at $\leq 21$ years were 0.35 times less at risk of developing breast cancer than those who gave birth of their first child $>21$ years (Table-I).

In our study, $28 \%$ respondents were either nulliparous or primipara, among them majority were from breast cancer group. Among the $72 \%$

Table-I

Distribution of respondents by age at birth of their first child

\begin{tabular}{|c|c|c|c|c|c|c|}
\hline \multirow{3}{*}{$\begin{array}{l}\text { Age at first child } \\
\text { (in completed } \\
\text { years) }\end{array}$} & \multicolumn{4}{|c|}{ Status of the respondents } & \multicolumn{2}{|c|}{ Total } \\
\hline & \multicolumn{2}{|c|}{ case } & \multicolumn{2}{|c|}{ control } & \multirow[b]{2}{*}{$\mathrm{N}$} & \multirow[b]{2}{*}{$\%$} \\
\hline & $\mathrm{N}$ & $\%$ & $\mathrm{~N}$ & $\%$ & & \\
\hline$\leq 21$ years & 213 & 81.3 & 260 & 99.2 & 473 & 90.1 \\
\hline$>21$ years & 49 & 18.7 & 2 & 0.8 & 51 & 9.9 \\
\hline Total & 262 & 100.0 & 262 & 100.0 & 524 & 100.0 \\
\hline
\end{tabular}

multi and grand multipara group majority were from control group. A highly significant $(\mathrm{p}=$ $<0.001$ ) association was found.

Regarding history of induced abortion, $57.4 \%$ had positive history, majority of them were from cases. About $43 \%$ had no history of induced abortion and majority was from control group $(\mathrm{OR}=20.62)$ (Fig-.3).

Mean duration of breast feeding was 2.08 (SD \pm .19) years for breast cancer cases and 2.53 (SD \pm .63) years for controls. A highly significant $(\chi 2$ $=227.971 ; \mathrm{df}=4 ; \mathrm{p}=<0.001, \mathrm{OR}=7.91$ ) association was found.

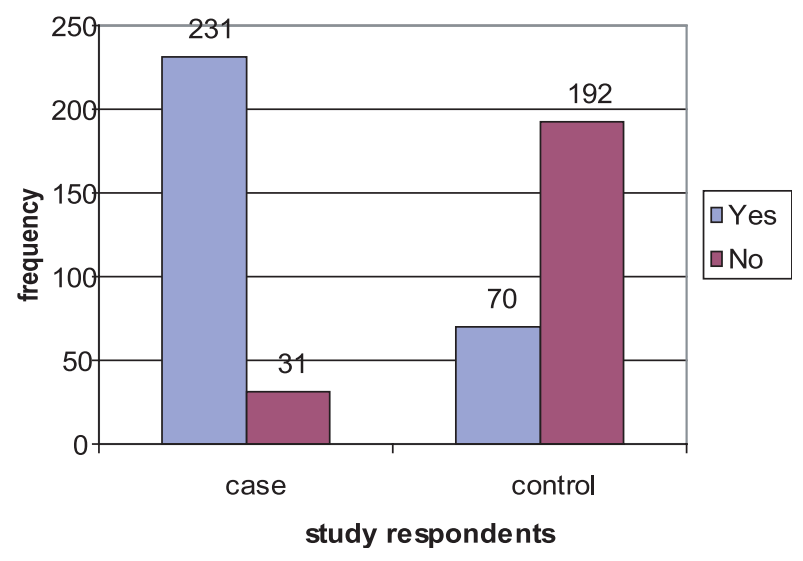

Fig-.3 Multiple bar diagram showing respondents' record on induced abortion 
Table-II

Summary table showing independent sample t test results

\begin{tabular}{lcccc}
\hline Variables & $\mathrm{t}$ & $\mathrm{df}$ & $\mathrm{P}$ value & Significance \\
\hline Age of the respondents at menarche & 2.82 & 400.00 & .005 & $\mathrm{~S}$ \\
Monthly family income & 8.51 & 381.73 & .000 & $\mathrm{HS}$ \\
Family member of the respondents & -.41 & 447.55 & .686 & $\mathrm{NS}$ \\
Number of live children born & -4.37 & 463.72 & .000 & $\mathrm{HS}$ \\
Duration of using OCP & -2.74 & 253.00 & .007 & $\mathrm{~S}$ \\
Height of the respondents in meters & 4.69 & 522.00 & .000 & $\mathrm{HS}$ \\
Waist circumference of the respondents in cm & -1.69 & 291.06 & .092 & $\mathrm{NS}$ \\
Hip circumference of the respondents in cm & 10.22 & 291.76 & .000 & $\mathrm{HS}$ \\
BMI of the respondents & 6.00 & 283.54 & .000 & $\mathrm{HS}$ \\
Waist Hip Ration & -21.82 & 279.93 & .000 & $\mathrm{HS}$ \\
\hline
\end{tabular}

* $\mathrm{S}=$ Significant, $\mathrm{HS}=$ Highly significant, $\mathrm{NS}=$ Not significant

About 49\% respondents used oral contraceptive pills, among them majority were from breast cancer group (OR=1.47). About $42 \%$ respondents used OCP for more than five years and majority was from breast cancer group. A highly significant $\left(\chi^{2}=92.080 ; \mathrm{df}=7 ; \mathrm{p}=<0.001\right)$ association was found (Table-II).

Among the respondents 53\% had menopause, majority were from control group $(\mathrm{OR}=0.22)$. Respondents' tobacco smoking habit shows that majority $(97 \%)$ was non smoker $(\mathrm{OR}=6.78)$. About 36\% respondents had regular physical activity, among them majority was from control group $(\mathrm{OR}=0.58)$.

About $14 \%$ respondents had personal history of breast disease and majority was from breast cancer group $(\mathrm{OR}=10.91)$ and eight controls had benign type of disease. About 20\% respondents had family history of breast disease and majority was from breast cancer group $(\mathrm{OR}=3.85)$. About $30 \%$ respondents had family history of other cancer among them majority was from breast cancer group $(\mathrm{OR}=2.21)$. About $3 \%$ respondents had $\mathrm{BMI} \geq 25$, among them all were from breast cancer group (Table-II).

\section{Discussion:}

This case-control study was conducted among five hundred and twenty four (524) respondents of both groups, aged 20 years and above from two selected hospitals of Dhaka city.
The mean age of the cases was $43.55(\mathrm{SD} \pm 9.63)$ years. Greater part $(28 \%)$ of the respondents was in 41-45 years group. This result does not accord with Olov $\mathrm{H} \mathrm{A}^{5}$ study, where majority $(85 \%)$ of breast cancer cases was above 50 years of age. The reason may be due to absent of birth registry in our country. Regarding marital status, $97 \%$ respondents were currently married. The entire widow's were from breast cancer group. Marital status is one of the important risk factors for developing breast cancer. In a case-control study done in Iran showed that never married women were at higher risk for breast cancer. ${ }^{6}$ In most studies single and nulliparous women were found to have increased risk for breast cancer as compared with parous women of the same age. ${ }^{7}$ However, in the Iranian study no association with parity emerged when multivariate analysis was performed. Evidence suggests that there is an interaction between marital status and parity, ${ }^{8}$ supporting a dual effect of parity on breast cancer risk with pregnancy. In addition, studies have reported that nulliparity reduces risk for breast cancer at younger age and elevates risk in the elderly. 9,10

About $79 \%$ respondents were housewife, among them majority was from control group and rest $11 \%$ were service holder. A significantly increased risk of breast cancer was observed for teachers and librarians. The observed 
increase in breast-cancer risk among teachers and librarians is consistent with earlier studies. Considering that teachers and librarians represent one of the largest single occupational groups among employed US women, further investigation of this association is wanted. ${ }^{11}$

In a study to determine occupation-specific risks of breast cancer among Swedish women employed in 1970. Excess risks were found for pharmacists, teachers of theoretical subjects, schoolmasters, systems analysts and programmers, telephone operators, telegraph and radio operators, metal platters and coaters, and hairdressers and beauticians, as well as for women working as physicians, religious workers, social workers, bankers, cost accountants, and telephone operators. While the high risks observed among professional, administrative, and clerical workers might be related to lower birth rates and increased case detection, excess risks found for telephone workers and for hairdressers and beauticians deserve further attention. 12

Several other factors are linked to breast cancer risk for reasons that are unknown. Women of high socioeconomic status are more likely than women of low socioeconomic status to develop breast cancer, and women who live in urban settings are more likely than women who live in rural settings to develop breast cancer. ${ }^{11,12}$

Respondents age at menarche shows that mean age was $11.73(\mathrm{SD} \pm 1.33)$ years for breast cancer cases and 11.47(SD \pm .71$)$ years for controls. Majority (54\%) had menarche at eleven or below age. This result does not accord with the study $^{13}$, where they found estrogen exposure is increased if a woman began menstruating at or before 11 years of age, or if she experiences menopause at age 55 years or older.

Respondents' mean age for giving birth of the first child was $19.41(\mathrm{SD} \pm 2.40$ ) years for the cases and 16.37 (SD \pm 1.16 ) years for the controls. Majority (68\%) had their first child at or below 18 years, among them majority were from control group. About 32\% had their first baby above 18 years and all were from breast cancer group. Respondents' mean parity was 3.26 (SD \pm 1.75 ) for breast cancer cases and 3.83 ( $\mathrm{SD} \pm 1.20$ ) for controls. About $28 \%$ respondents was either nulliparous or primipara, among them majority were from breast cancer group. Among the $72 \%$ multi and grand multipara group majority were from control group. This result accords with the Kamal et. al., ${ }^{13}$ studies, where they found women who have never given birth was more likely to develop breast cancer after menopause than women who have given multiple births. The timing of first pregnancy also appears to play a role; women who have their first full-term pregnancy at the age of 30 years or older have an increased risk of breast cancer as compared to women who give birth before age 30.There are lot of studies to prove the hypothesis that breast- feeding affords some protection against the disease. The majority of these studies were performed in welldeveloped countries where breast cancer risk is high and duration of breast feeding is not prolonged. ${ }^{13}$

Regarding history of induced abortion, $57 \%$ had positive history, majority of them were cases. Mean duration of breast feeding was 2.08 (SD \pm .19) years for breast cancer cases and 2.52 (SD \pm .63) years for controls. Respondents by history of using oral contraceptive pills show that $49 \%$ uses OCP, among them majority were from breast cancer group, this result accords with Kamal et al., study. ${ }^{13}$

Mean duration of oral contraceptive pill user for breast cancer cases $6.53(\mathrm{SD} \pm 2.94)$ years and for controls $5.48(\mathrm{SD} \pm 3.16)$ years. Majority $(58 \%)$ of the respondents used pills for five or less years, among them most were from control group. About $42 \%$ respondents used OCP for more than five years and majority was from breast cancer group. Respondents by history of using injectable contraceptives show that $28 \%$ used injectable contraceptives, among them majority was from control group. Respondents by history of menopause shows that $53 \%$ had menopause, among them majority were from control group.

Majorities (97\%) of the respondents were non smoker and only 3\% was smoker. All the 
smokers were from breast cancer group. Epidemiological investigations of the relations between smoking and breast cancer have yielded conflicting results. Several studies have suggested that smoking may decrease the risk of breast cancer. Others have reported no evident association, while a few have suggested that smoking may increase the risk of breast cancer, especially in pre-menopausal women. 14

About 36\% respondents had regular physical activity, among them majority was from control group. About $20 \%$ respondents had family history of breast disease and majorities were from breast cancer group. About 30\% respondents had family history of other cancer among them majority was from breast cancer group. About $3 \%$ respondents had BMI $\geq 25$, among them all were from breast cancer group. Women who have had cancer in one breast have an increased risk of developing cancer in the other breast. This is especially true if a woman has an inherited BRCA mutation. Women who have been diagnosed with cancer of the endometrium, ovary, or colon are more likely to develop breast cancer than women who do not have these cancers. ${ }^{14}$

\section{References:}

1. Ferrero JM, Namer M. Epidemiology of cancer of the breast. Arch Anat Cytol Pathol 1994; 42(5): 198-205.

2. Gatta G, Capocaccia R, Coleman MP, et al. Toward a comparison of survival in American and European cancer patients. Cancer 2000; 89: 893-900.

3. Karjalainen S, Pukkala E. Social class as a prognostic factor in breast cancer survival. Cancer 1990; 66: 819-26.
4. Lwonga SK, Lemeshow, Sample size determination in health studies- A practical manual. WHO, Geneva, 1991. 6-7

5. Olov H A, Malker B, Olav M, et al., Age as a Prognostic Factor in Breast Cancer: Cancer 1985; 56: 898-902.

6. Ebrahim M, Vahdaninia M, Montazeri A. Risk factors for breast cancer in Iran: a case- control study Available online http://breast-cancerresearch.com/content/4/5/R10. Dated: 22.03.07

7. Rosner B, Colditz GA, Willett WC. Reproductive risk factors in a prospective study of breast cancer: the Nurses' Health Study. Am J Epidemiol 1994, 139: 819-35.

8. McCredie M, Paul C, Skegg DCG, Wiliams S. Reproductive factors and breast cancer in New Zealand. Int J Cancer 1998; 76: 182-8.

9. Lipworth I. Epidemiology of breast cancer. Eur J Cancer Prev 1995; 4: 7-30.

10. Tavani A, Gallus S, La Vecchia C, Negri E, Montella M, Dal Maso L, et al. Risk factors for breast cancer in women under 40 years. Eur J Cancer 1999; 35: 1361-7.

11. Zheng T, Holford TR, Taylor MS, Luo J, et al. A case-control study of occupation and breast-cancer risk in Connecticut. J Cancer Epidemiol Prev 2002; 7(1): 11-9.

12. Pollán M, Gustavsson P. High-risk occupations for breast cancer in the Swedish female working population. Am J Pub Health 1999; 89(6): 87581.

13. Abou-Daoud KT. Cancer of the breast and breastfeeding: study of 279 parous women and matched controls. Cancer 1971; 32: 67-9.

14. Rohan T.E, Baron JA, Cigarette smoking and breast cancer. Am J Epidemiol 1989; 129(1): 3642 . 